\title{
AMIDO E HIPOCLORITO DE SÓDIO NO ENRAIZAMENTO IN VITRO DO ABACAXIZEIRO 'GOLD' E SEUS EFEITOS NA ACLIMATIZAÇÃO'
}

\author{
RODRIGO DA SILVA OLIVEIRA², MONIQUE RODRIGUES PEREIRA ${ }^{3}$, \\ VIRGINIA SILVA CARVALHO ${ }^{4}$, ELIZABETH DE FÁTIMA LUCAS ${ }^{5}$, \\ GERALDO DE AMARAL GRAVINA ${ }^{6}$
}

RESUMO-Este trabalho teve como objetivo avaliar a substituição total ou parcial do ágar por amidos de milho e mandioca e da esterilização física em autoclave pela esterilização química com hipoclorito de sódio ( $\mathrm{NaClO}$ ) no desenvolvimento de mudas de abacaxizeiro 'Gold' (Ananas comosus). Como agentes geleificantes, foram utilizados: M1: ágar (6,0 $\left.\mathrm{g} \mathrm{L}^{-1}\right)$; M2: amido de milho (60,0 $\left.\mathrm{g} \mathrm{L}^{-1}\right)$; M3: ágar $\left(3,0 \mathrm{~g} \mathrm{~L}^{-1}\right)+$ amido de milho (30,0 $\left.\mathrm{g} \mathrm{L}^{-1}\right)$, e M4: ágar (3,0 $\left.\mathrm{g} \mathrm{L}^{-1}\right)+$ amido de mandioca $\left(30,0 \mathrm{~g} \mathrm{~L}^{-1}\right)$. As esterilizações foram feitas por meio da autoclavagem a $121^{\circ} \mathrm{C}$ e da utilização de soluções de $\mathrm{NaClO}$ nas concentrações de $0,003 \%$ para o enxágue das vidrarias e $0,0003 \%$ para adição ao meio de cultivo. Após um mês de cultivo in vitro, não houve influência negativa do $\mathrm{NaClO}$ e dos agentes geleificantes no enraizamento das brotações para a maioria dos parâmetros avaliados. As mudas produzidas in vitro foram levadas para aclimatização em casa de vegetação, por 90 dias. Na aclimatização, as mudas oriundas dos tratamentos com esterilização química não diferiram das oriundas dos meios autoclavados em nenhum parâmetro avaliado, enquanto a combinação ágar + amido de milho proporcionou resultados inferiores entre os agentes geleificantes.

Termos para indexação: Ananas comosus var. comosus, esterilização química, agente geleificante, amido de milho, amido de mandioca, propagação in vitro.

\section{STARCH AND SODIUM HIPOCHLORITE ON IN VITRO ROOTING OF PINEAPPLE ‘GOLD’ AND ITS EFFECTS ON ACCLIMATIZATION}

\begin{abstract}
This study aimed to evaluate the total or partial replacement of agar by corn starch and cassava starch and physical sterilization in autoclave for chemical sterilization with sodium hypochlorite $(\mathrm{NaClO})$ in development of pineapple 'Gold' plantlets. The gelling agents used were: M1: agar $\left(6.0 \mathrm{~g} \mathrm{~L}^{-1}\right)$; M2: corn $\operatorname{starch}\left(60.0 \mathrm{~g} \mathrm{~L}^{-1}\right)$; M3: agar $\left(3.0 \mathrm{~g} \mathrm{~L}^{-1}\right)+\operatorname{corn} \operatorname{starch}\left(30.0 \mathrm{~g} \mathrm{~L}^{-1}\right)$ and M4: agar $\left(3.0 \mathrm{~g} \mathrm{~L}^{-1}\right)+$ cassava starch (30.0 $\left.\mathrm{g} \mathrm{L}^{-1}\right)$. The sterilizations were made by autoclaving at $121^{\circ} \mathrm{C}$ or by using the solutions of $\mathrm{NaClO}$ at the concentrations of $0,003 \%$ to rinse the glassware and $0,0003 \%$ for addition to the culture medium. After one month of in vitro cultivation, it was observed no negative influence of $\mathrm{NaClO}$ and gelling agents in the rooting in vitro of shoots for most parameters evaluated. The plantlets derived from in vitro phase were taken to acclimatization in greenhouse for 90 days. During the acclimatization, the plantlets derived from treatments with chemical sterilization did not differ from the ones derived of autoclaved media to any parameter evaluated, whereas the combination agar + corn starch provided inferior results among gelling agents.

Index terms: Ananas comosus var. comosus, chemical sterilization, gelling agent, corn starch, cassava starch, in vitro propagation.
\end{abstract}

\footnotetext{
${ }^{1}$ (Trabalho 120-14). Recebido em: 01-04-2014. Aceito para publicação em: 10-11-2014.Parte da monografia de conclusão de curso do primeiro autor. UENF

${ }^{2}$ Engenheiro Agrônomo UENF/CCTA/LFIT. E-mail: oliveira_r_s@hotmail.com

${ }^{3}$ Mestranda em Produção Vegetal UENF/CCTA/LFIT. E-mail: moniquerodriguesp@yahoo.com.br

${ }^{4}$ Dra. em Fitotecnia, Professora Associada UENF/CCTA/LFIT. E-mail: virginia@uenf.br

${ }^{5}$ Tecnóloga em Horticultura, Bolsista de Extensão UENF/CCTA/LFIT. E-mail: bethdefatima@gmail.com

${ }^{6}$ Dr. em Fitotecnia, Professor Associado UENF/CCTA/LEAG. E-mail: gravina@uenf.br
} 


\section{INTRODUÇÃO}

O abacaxizeiro (Ananas comosus var. comosus) é cultivado em mais de 50 países, sendo Filipinas, Brasil, Costa Rica, Tailândia e China os maiores produtores. É a sexta fruteira mais plantada no Brasil, ocupando uma área de mais de 80.500 ha, sendo que as regiões Nordeste e Sudeste lideram a produção, representando, respectivamente, 39,46\% e $33,13 \%$ do total nacional (FAO, 2013; IBGE, 2013).

Pertencente ao grupo Smooth Cayenne, a cultivar Gold ou MD2 destaca-se pelo alto teor de açúcar e pela ausência de espinhos nas folhas, o que facilita a manipulação e os tratos culturais na lavoura. Por apresentar baixo teor de acidez e elevada durabilidade pós-colheita, esta cultivar tem tido grande aceitação no mercado consumidor, sendo indicada aos produtores que visam à comercialização no mercado internacional (BARREIRO NETO et al., 2007; BARTHOLOMEW, 2009).

A maior parte das lavouras comerciais de abacaxizeiro utiliza-se de material propagativo oriundo do próprio campo, constituído por mudas obtidas de brotações laterais da planta. Este tipo de manejo ocasiona a disseminação de pragas e enfermidades, reduzindo a produtividade da lavoura (REINHARDT; CUNHA, 2006).

A propagação in vitro ou micropropagação do abacaxizeiro permite a produção de grande quantidade de mudas de alta qualidade fitossanitária, isentas das principais doenças que acometem a cultura. Contudo, as mudas produzidas por técnicas de cultivo in vitro possuem custo elevado em comparação às técnicas convencionais, destacando-se a necessidade de mão de obra especializada e da infraestrutura das biofábricas (SOUZA; JUNGHANS, 2006).

Para garantir a assepsia do meio de cultivo e dos utensílios utilizados em seu preparo, recorrese à esterilização física realizada em equipamentos denominados autoclaves. O hipoclorito de sódio $(\mathrm{NaClO})$ é um produto com atividade biocida, de baixo custo e que se apresenta como alternativa à autoclavagem, que é uma operação dispendiosa e com elevado consumo de energia elétrica (EMMANUEL et al., 2004). Além disso, diversos trabalhos têm apresentado bons resultados com a utilização do $\mathrm{NaClO}$ como agente químico esterilizante no cultivo in vitro de diversas espécies (TEIXEIRA et al., 2006; RIBEIRO; TEIXEIRA, 2007; TEIXEIRA et al., 2008).

$\mathrm{O}$ agente geleificante mais utilizado nos meios de cultivo é o ágar, que constitui o componente químico de maior custo no preparo dos meios. Com o objetivo de substituir o ágar por polissacarídeos de menor custo, estudos com a utilização de amidos de milho e de mandioca têm conseguido eficiente geleificação dos meios, associado ao bom desenvolvimento das plantas (FERRI et al., 1998; ERIG et al., 2004; COSTA et al., 2007; PEREIRA, 2011).

O objetivo desta pesquisa foi avaliar a substituição total ou parcial do ágar por amidos de milho e mandioca e da esterilização física em autoclave pela esterilização química com hipoclorito de sódio no crescimento e no desenvolvimento de mudas de abacaxizeiro 'Gold', visando à produção de mudas de alta qualidade fisiológica e fitossanitária e reduzindo os custos de produção das mudas.

\section{MATERIAL E MÉTODOS}

\section{Enraizamento in vitro}

O experimento foi realizado no Laboratório de Fitotecnia da Universidade Estadual do Norte Fluminense Darcy Ribeiro (UENF), localizada no município de Campos dos Goytacazes-RJ (latitude: $21^{\circ} 19^{\prime} 23^{\prime \prime}$; longitude: $41^{\circ} 10^{\prime} 40^{\prime \prime} \mathrm{W}$; altitude: $14 \mathrm{~m}$ ).

$\mathrm{O}$ meio utilizado no enraizamento dos explantes foi composto pelos sais de MS e pelas vitaminas de White (MURASHIGE; SKOOG, 1962), $30 \mathrm{~g} \mathrm{~L}^{-1}$ de sacarose e $100 \mathrm{mg} \mathrm{L}^{-1}$ de mioinositol. As brotações utilizadas neste experimento foram oriundas do Laboratório Biomudas, situado no município de Venda Nova do Imigrante-ES, e estavam em último subcultivo em meio de multiplicação.

As combinações de agentes geleificantes constituíram-se de: M1: ágar bacteriológico Vetec ${ }^{\circledR}$ $\left(6,0 \mathrm{~g} \mathrm{~L}^{-1}\right) ; \mathrm{M} 2$ : amido de milho Maizena ${ }^{\circledR}(60,0$ $\left.\mathrm{g} \mathrm{L}^{-1}\right)$; M3: ágar $\left(3,0 \mathrm{~g} \mathrm{~L}^{-1}\right)+$ amido de milho Maizena $^{\circledR}\left(30,0 \mathrm{~g} \mathrm{~L}^{-1}\right)$ e M4: ágar $\left(3,0 \mathrm{~g} \mathrm{~L}^{-1}\right)+$ amido de mandioca Amafil ${ }^{\circledR}\left(30,0 \mathrm{~g} \mathrm{~L}^{-1}\right)$. A esterilização física foi realizada em autoclave a $1,0 \mathrm{~atm}$ e $121{ }^{\circ} \mathrm{C}$ por 20 minutos. Na esterilização química utilizouse de uma solução de hipoclorito de sódio na concentração de $0,003 \%$ para o enxágue dos frascos e utensílios e outra a $0,0003 \%$ para adição ao meio de cultivo (TEIXEIRA et al., 2006). Toda a etapa de esterilização química foi realizada em câmara de fluxo laminar, onde os frascos foram enxaguados e o $\mathrm{NaClO}$ foi adicionado ao meio de cultivo após este ser fervido. Após a excisão das raízes e das folhas, de modo a uniformizar as brotações, estas foram colocadas nos frascos com os respectivos meios de enraizamento e levadas para sala de cultivo, onde permaneceram por 30 dias.

Após a passagem das brotações para os meios de cultivo propostos, elas foram mantidas 
em sala de cultivo à temperatura de $27 \pm 2{ }^{\circ} \mathrm{C}$ e irradiância de $25 \mu \mathrm{mol} \mathrm{m}{ }^{-2} \mathrm{~s}^{-1}$, provida por lâmpadas fluorescentes $\left(\mathrm{OSRAM}^{\circledR}\right.$, semelhante à luz do dia) e fotoperíodo de 16:8 horas (luz:escuro). Ao final do enraizamento in vitro, foram avaliados a porcentagem de sobrevivência, a massa da matéria fresca e seca e o número de folhas e de raízes em metade das mudas de cada tratamento (12 plantas), sendo a outra metade levada para a etapa de aclimatização.

Foi utilizado o delineamento inteiramente casualizado, com oito tratamentos, sendo estes instalados em esquema fatorial 4 × 2 (quatro combinações de agentes geleificantes e duas formas de esterilização do meio de cultura e vidrarias). Cada tratamento contou com seis repetições, sendo cada repetição constituída por um frasco de cultivo com $40 \mathrm{~mL}$ de meio de enraizamento contendo quatro brotações.

\section{Aclimatização}

A aclimatização foi realizada em casa de vegetação com cobertura de plástico $(100 \mu \mathrm{m})$ e Sombrite $^{\circledR} 50 \%$ na Unidade de Apoio à Pesquisa do Centro de Ciências e Tecnologias Agropecuárias da UENF, no período de junho a setembro de 2012.

As mudas foram plantadas em bandejas de poliestireno expandido de 200 células, com um volume em torno de $18,3 \mathrm{~cm}^{3}$ por célula, preenchidas com o substrato Plantmax ${ }^{\circledR}$ Hortaliças.

O delineamento experimental foi o de blocos casualizados, com esquema fatorial 4 × 2 , com três repetições e quatro plantas por parcela, seguindo os mesmos tratamentos das mudas conduzidas in vitro. Antes do plantio, as mudas foram submetidas à lavagem em água corrente para a retirada do meio de cultivo aderido às raízes. Foram adicionadas adubações a cada 15 dias, com $3 \mathrm{~mL} /$ planta da solução nutritiva de Hoagland e Arnon (1950) (RESH, 1997).

Ao final da aclimatização, foram avaliados os seguintes parâmetros: porcentagem de sobrevivência, número de folhas, altura e diâmetro da roseta, massa da matéria fresca, área foliar, volume de raiz, massa da matéria seca da parte aérea, da raiz e total, fluorescência da clorofila $a$ (eficiência fotoquímica) e índice fotossintético (PI). A fluorescência da clorofila $a$ e o PI foram determinados por meio de um fluorímetro não modulado modelo Pocket PEA Chlorophyll Fluorimeter (Hansatech Instruments - King's Lynn, Norfolk). Para estas duas últimas variáveis, foi avaliada uma folha por planta.

Os dados foram submetidos aos testes de Lilliefors e Bartlett para a verificação da normalidade dos dados e homogeneidade de variâncias entre os tratamentos. Em seguida, foram submetidos à Análise de Variância (ANOVA), e as médias foram comparadas pelo teste de Tukey, a $5 \%$ de probabilidade, utilizando o programa $\mathrm{SAEG}^{\circledR}$ (SAEG, 2007).

\section{RESULTADOS E DISCUSSÃO}

\section{Enraizamento in vitro}

Após um mês de cultivo in vitro, a porcentagem de sobrevivência das brotações foi de $100 \%$ para todos os tratamentos.

Não foram observadas diferenças significativas entre os agentes geleificantes e as esterilizações para os parâmetros massa da matéria fresca, número de folhas, massa da matéria seca da parte aérea e massa da matéria seca total.

A esterilização química do meio de cultura geleificado com amido de mandioca resultou em plantas com menor número de raízes em comparação à autoclavagem, não diferindo nos demais agentes geleificantes (Tabela 1). Para o parâmetro massa da matéria seca de raiz, a esterilização física foi inferior à química no meio geleificado com ágar + amido de milho, enquanto nos outros meios não houve diferença. Entre os agentes geleificantes nos meios esterilizados quimicamente, as combinações de ágar com amido de milho e amido de mandioca (M3 e M4, respectivamente) proporcionaram as maiores médias (Tabela 1).

No enraizamento in vitro das brotações, a esterilização química proporcionou resultado semelhante ou superior à autoclavagem para a maioria dos parâmetros analisados, enquanto entre os agentes geleificantes não foi observada diferença significativa entre os valores, em quase todos os casos, exceto para a massa da matéria seca de raiz, cujos seus valores diferiram nos meios esterilizados quimicamente.

\section{Aclimatização}

A menor taxa de sobrevivência (91\%) foi verificada nas plantas cultivadas nos meios de cultivo geleificados com ágar + amido de mandioca (M4), em ambas as formas de esterilização, e no meio geleificado com ágar + amido de milho (M3) esterilizado quimicamente. Para os demais tratamentos, a sobrevivência das mudas foi de 100\% (dados não mostrados).

A esterilização química foi igual à autoclavagem em todos os meios de cultivo, para todos os parâmetros avaliados. Entre os meios esterilizados quimicamente, não houve diferença significativa entre os agentes geleificantes. Não houve diferença significativa entre os agentes geleificantes e os dois tipos de esterilização para 
número de folhas e massa da matéria seca de raiz (dados não mostrados).

Para massa da matéria fresca, massa da matéria seca da parte aérea, massa da matéria seca total e diâmetro da roseta, as plantas oriundas dos meios autoclavados e geleificados com ágar + amido de milho apresentaram desenvolvimento inferior ao daquelas cultivadas nos demais agentes geleificantes (Tabela 2). Para os parâmetros altura da roseta e volume radicular, o amido de milho puro proporcionou resultado semelhante ou superior aos resultados dos promovidos pelos outros agentes geleificantes nos meios autoclavados (Tabela 2). Os meios de cultivo geleificados com ágar e ágar + amido de mandioca, dentro da esterilização física, proporcionaram plantas com maior área foliar do que o meio com ágar + amido (Tabela 2).

Quanto aos meios esterilizados fisicamente, de modo geral, constatou-se que a combinação M3 (ágar + amido de milho) propiciou os piores resultados para a maior parte das variáveis, enquanto o amido de milho usado de forma isolada ou o amido de mandioca em combinação com ágar não diferiram do tratamento-controle (ágar) em nenhum caso.

A Figura 1 refere-se à eficiência fotoquímica do fotossistema II. De acordo com BolhàrNordenkampf et al. (1989), a relação Fv/Fm pode variar entre 0,75 e 0,85 em plantas não submetidas a estresse. Observa-se nesta Figura que os valores se encontram um pouco abaixo desta referência, mostrando que, provavelmente, as plantas tenham apresentado algum tipo de estresse, sobretudo relacionado à saída do ambiente in vitro para o $e x$ vitro, que se caracteriza pela drástica mudança nas condições ambientais. A relação Fv/Fm, na qual Fm é a fluorescência máxima e Fv é a fluorescência variável, possui elevada relação positiva com o rendimento quântico da fotossíntese, sendo a variável mais utilizada para detectar danos ao aparato fotossintético em plantas (KAO; FORSETH, 1992).

Após a retirada do ambiente in vitro, a relação Fv/Fm pode sofrer uma grande redução, provocada principalmente pela alta intensidade luminosa. $\mathrm{Na}$ fase de aclimatização, as mudas são expostas à alta densidade de fluxo de fótons fotossintéticos e à baixa umidade relativa, o que ocasiona fotoinibição e estresse hídrico, podendo, inclusive, levá-las à morte (VAN HUYLENBROECK et al., 2000).

$\mathrm{O}$ índice fotossintético (PI) serve para avaliar o desempenho de plantas submetidas a condições de estresse e seu índice de vitalidade (STRASSER et al., 2000; STRASSER et al., 2004). As mudas de todos os tratamentos apresentaram comportamento semelhante com relação a esta variável, indicando que os agentes geleificantes alternativos e a esterilização química com $\mathrm{NaClO}$ não influenciaram em seu desenvolvimento (Figura 2). Uma vez que a variável PI mostra a atividade dos fotossistemas I e II (STRASSER et al., 2000; STRASSER et al., 2004), pode-se sugerir que as mudas oriundas do cultivo in vitro nos meios propostos não sofreram danos no aparato fotossintético e estavam em boas condições durante a aclimatização.

Constatou-se que, quando os meios foram esterilizados quimicamente, os agentes geleificantes não diferiram entre si em nenhum dos parâmetros biométricos analisados, sugerindo que é possível a substituição do ágar por qualquer um dos demais agentes geleificantes quando o meio de cultivo estiver quimicamente esterilizado. Nesta pesquisa, ficou evidenciado que a esterilização química dos meios de cultivo e das vidrarias com $\mathrm{NaClO}$ foi tão eficiente quanto a autoclavagem, garantindo a total assepsia dos mesmos sem que houvesse interferência negativa no crescimento das plantas.

Os resultados encontrados neste trabalho confirmam os obtidos por outros autores, como Teixeira et al. (2006), avaliando Ananas comosus cv. Smooth Cayenne Teixeira et al. (2008), em estudos com Eucalyptus pellita, Ribeiro e Teixeira (2007), ao avaliarem o comportamento de Sequoia sempervirens, Tiwari et al., (2012) e Sawant e Tawar (2011), ambos desenvolvendo suas pesquisas com Saccharum officinarum. Em todos esses trabalhos, foi obtida a completa assepsia do meio de cultura utilizando $\mathrm{NaClO}$ como agente químico esterilizante.

$\mathrm{O}$ uso de agentes geleificantes alternativos ao ágar pode significar a redução total ou parcial deste componente tão dispendioso no preparo de meios de cultivo, contribuindo para reduzir os custos na micropropagação comercial de plantas. A substituição total do ágar por amido de milho, ou parcial pelo amido de mandioca, mostrou-se eficaz na geleificação dos meios de cultivo, além de proporcionar resultados estatisticamente iguais ou mesmo superiores no desenvolvimento das mudas. Resultados semelhantes foram observados por Pereira (2011), que também avaliou o comportamento do abacaxizeiro, Erig et al. (2004) e Ferri et al. (1998), ambos avaliando a macieira, e Costa et al. (2007), que desenvolveram suas pesquisas com abacaxizeiro e bananeira. 
TABELA 1- Número de raízes (NR) e massa da matéria seca de raízes (MSR) em mudas de abacaxizeiro 'Gold' (Ananas comosus var. comosus) após 30 dias de cultivo em meio de enraizamento in vitro, em função dos agentes geleificantes e formas de esterilização. Campos dos Goytacazes-RJ.

\begin{tabular}{|c|c|c|c|c|c|c|}
\hline \multirow{2}{*}{ AG } & \multicolumn{2}{|c|}{ NR } & \multirow{2}{*}{ Média } & \multicolumn{2}{|c|}{$\operatorname{MSR}\left(10^{-3} \mathrm{~g}\right)$} & \multirow{2}{*}{ Média } \\
\hline & $\mathrm{EF}$ & EQ & & $\mathrm{EF}$ & EQ & \\
\hline M1 & $1,94 \mathrm{~A} \mathrm{a}$ & $2,04 \mathrm{~A} \mathrm{a}$ & 1,99 & $6,5 \mathrm{~A} \mathrm{a}$ & $3,3 \mathrm{Ab}$ & 4,90 \\
\hline M2 & $3,08 \mathrm{~A} \mathrm{a}$ & $0,92 \mathrm{~B}$ a & 2,00 & $2,8 \mathrm{~A} \mathrm{a}$ & $2,3 \mathrm{~A} \mathrm{~b}$ & 2,55 \\
\hline M3 & $2,35 \mathrm{~A} \mathrm{a}$ & $2,41 \mathrm{~A} \mathrm{a}$ & 2,38 & $4,8 \mathrm{~B} \mathrm{a}$ & $11,1 \mathrm{~A} \mathrm{a}$ & 7,95 \\
\hline M4 & $1,14 \mathrm{~A} \mathrm{a}$ & $1,63 \mathrm{~A} \mathrm{a}$ & 1,38 & $2,6 \mathrm{~A} \mathrm{a}$ & $4,4 \mathrm{~A} \mathrm{ab}$ & 3,50 \\
\hline Média & 2,13 & 1,75 & & 4,2 & 5,3 & \\
\hline $\mathrm{CV}(\%)$ & \multicolumn{2}{|c|}{56,78} & \multicolumn{3}{|c|}{82,87} & \\
\hline
\end{tabular}

Médias seguidas pelas mesmas letras maiúsculas na horizontal e minúsculas na vertical não diferem entre si, pelo teste de Tukey, a 5\% de probabilidade. AG: agente geleificante; M1: ágar; M2: amido de milho; M3: ágar + amido de milho; M4: ágar + amido de mandioca; EF: esterilização física; EQ: esterilização química.

TABELA 2 - Massa da matéria fresca (MF), diâmetro da roseta (DR), área foliar (AF), altura da roseta (AR), volume de raízes (VR), massa da matéria seca da parte aérea (MSA) e massa da matéria seca total (MST) de mudas de abacaxizeiro 'Gold' (Ananas comosus var. comosus) oriundas de cultivo in vitro, após 90 dias de aclimatização em casa de vegetação. Campos dos Goytacazes - RJ.

\begin{tabular}{|c|c|c|c|c|c|c|c|c|c|}
\hline \multirow{2}{*}{$\mathrm{AG}$} & \multicolumn{2}{|c|}{$\mathrm{MF}(\mathrm{g})$} & \multicolumn{3}{|c|}{$\mathrm{DR}(\mathrm{cm})$} & \multirow{2}{*}{ Média } & \multicolumn{2}{|c|}{$\mathrm{AF}\left(\mathrm{cm}^{2}\right)$} & \multirow{2}{*}{ Média } \\
\hline & $\mathrm{EF}$ & EQ & & $\mathrm{EF}$ & EQ & & $\mathrm{EF}$ & EQ & \\
\hline M1 & $3,90 \mathrm{~A} \mathrm{a}$ & $4,00 \mathrm{~A} \mathrm{a}$ & 3,95 & $10,55 \mathrm{~A} \mathrm{a}$ & $10,47 \mathrm{~A} \mathrm{a}$ & 10,51 & $38,30 \mathrm{~A} \mathrm{a}$ & $38,12 \mathrm{~A} \mathrm{a}$ & 38,21 \\
\hline M2 & $3,78 \mathrm{~A} \mathrm{a}$ & $3,41 \mathrm{~A} \mathrm{a}$ & 3,59 & $10,77 \mathrm{~A} \mathrm{a}$ & $10,03 \mathrm{~A} \mathrm{a}$ & $10,04 \quad 3$ & $36,42 \mathrm{~A} \mathrm{ab}$ & $36,96 \mathrm{~A} \mathrm{a}$ & 36,68 \\
\hline M3 & $2,54 \mathrm{~A} \mathrm{~b}$ & $3,07 \mathrm{~A} \mathrm{a}$ & 2,81 & $8,26 \mathrm{~A} \mathrm{~b}$ & $9,13 \mathrm{~A} \mathrm{a}$ & 8,69 & $26,49 \mathrm{~A} \mathrm{~b}$ & $30,86 \mathrm{~A} \mathrm{a}$ & 28,68 \\
\hline M4 & $3,76 \mathrm{~A} \mathrm{a}$ & $3,26 \mathrm{~A} \mathrm{a}$ & 3,51 & $10,42 \mathrm{~A} \mathrm{a}$ & $9,93 \mathrm{~A} \mathrm{a}$ & 10,18 & $37,53 \mathrm{~A} \mathrm{a}$ & $33,81 \mathrm{~A} \mathrm{a}$ & 35,67 \\
\hline Média & 3,49 & 3,44 & & 10,00 & 9,89 & & 34,68 & 34,94 & \\
\hline $\mathrm{CV}(\%)$ & \multicolumn{2}{|c|}{28,70} & & \multicolumn{2}{|c|}{17,91} & \multicolumn{4}{|c|}{28,53} \\
\hline \multirow{2}{*}{$\mathrm{AG}$} & \multicolumn{4}{|c|}{$\mathrm{AR}(\mathrm{cm})$} & Mádi & \multicolumn{3}{|c|}{$\operatorname{VR}\left(\mathrm{cm}^{3}\right)$} & \multirow{2}{*}{ Média } \\
\hline & & EF & & EQ & iviend & $\mathrm{EF}$ & & $Q$ & \\
\hline M1 & \multicolumn{2}{|c|}{$1,60 \mathrm{~A} \mathrm{ab}$} & \multicolumn{2}{|c|}{$1,51 \mathrm{~A} \mathrm{a}$} & 1,55 & $0,50 \mathrm{~A} a b$ & \multicolumn{2}{|c|}{$0,57 \mathrm{~A} \mathrm{a}$} & 0,54 \\
\hline M2 & \multicolumn{2}{|c|}{$1,69 \mathrm{~A} \mathrm{a}$} & \multicolumn{2}{|c|}{$1,57 \mathrm{~A} \mathrm{a}$} & 1,64 & $0,64 \mathrm{~A} \mathrm{a}$ & \multicolumn{2}{|c|}{$0,54 \mathrm{~A} \mathrm{a}$} & 0,59 \\
\hline M3 & \multicolumn{2}{|c|}{$1,36 \mathrm{~A} \mathrm{~b}$} & \multicolumn{2}{|c|}{$1,50 \mathrm{~A} \mathrm{a}$} & 1,43 & $0,39 \mathrm{~A} \mathrm{~b}$ & & $5 \mathrm{~A} \mathrm{a}$ & 0,43 \\
\hline M4 & &, $53 \mathrm{~A} \mathrm{ab}$ & & $72 \mathrm{~A} \mathrm{a}$ & 1,63 & $0,54 \mathrm{~A} \mathrm{ab}$ & & $8 \mathrm{~A} \mathrm{a}$ & 0,56 \\
\hline Média & & 1,55 & & 1,57 & & 0,52 & & 54 & \\
\hline $\mathrm{CV}(\%)$ & & &, 39 & & & & 34,79 & & \\
\hline$\Delta G$ & & Ms & $\mathrm{A}(\mathrm{g})$ & & Média & & $\operatorname{MST}(\mathrm{g})$ & & Média \\
\hline AU & & $\mathrm{EF}$ & & EQ & ivicura & $\mathrm{EF}$ & & $\mathrm{EQ}$ & ivicura \\
\hline M1 & & $0,39 \mathrm{~A} \mathrm{a}$ & &, $38 \mathrm{~A} \mathrm{a}$ & 0,39 & $0,51 \mathrm{~A} \mathrm{a}$ & & $9 \mathrm{~A} \mathrm{a}$ & 0,51 \\
\hline M2 & & $0,35 \mathrm{~A} \mathrm{a}$ & &, $33 \mathrm{~A} \mathrm{a}$ & 0,34 & $0,48 \mathrm{~A} \mathrm{a}$ & & $8 \mathrm{~A} \mathrm{a}$ & 0,48 \\
\hline M3 & & , $23 \mathrm{Ab}$ & & $28 \mathrm{~A} \mathrm{a}$ & 0,26 & $0,31 \mathrm{Ab}$ & & $8 \mathrm{~A} \mathrm{a}$ & 0,34 \\
\hline M4 & & $0,36 \mathrm{~A} \mathrm{a}$ & &, $31 \mathrm{~A} \mathrm{a}$ & 0,34 & $0,47 \mathrm{~A} \mathrm{a}$ & & $9 \mathrm{~A} \mathrm{a}$ & 0,43 \\
\hline Média & & 0,34 & & 0,33 & & 0,44 & & 0,44 & \\
\hline $\mathrm{CV}(\%)$ & & &, 90 & & & & 34,80 & & \\
\hline
\end{tabular}

Médias seguidas pelas mesmas letras maiúsculas na horizontal e minúsculas na vertical não diferem entre si, pelo teste de Tukey, a 5\% de probabilidade. AG: agente geleificante; M1: ágar; M2: amido de milho; M3: ágar + amido de milho; M4: ágar + amido de mandioca; EF: esterilização física; EQ: esterilização química. 


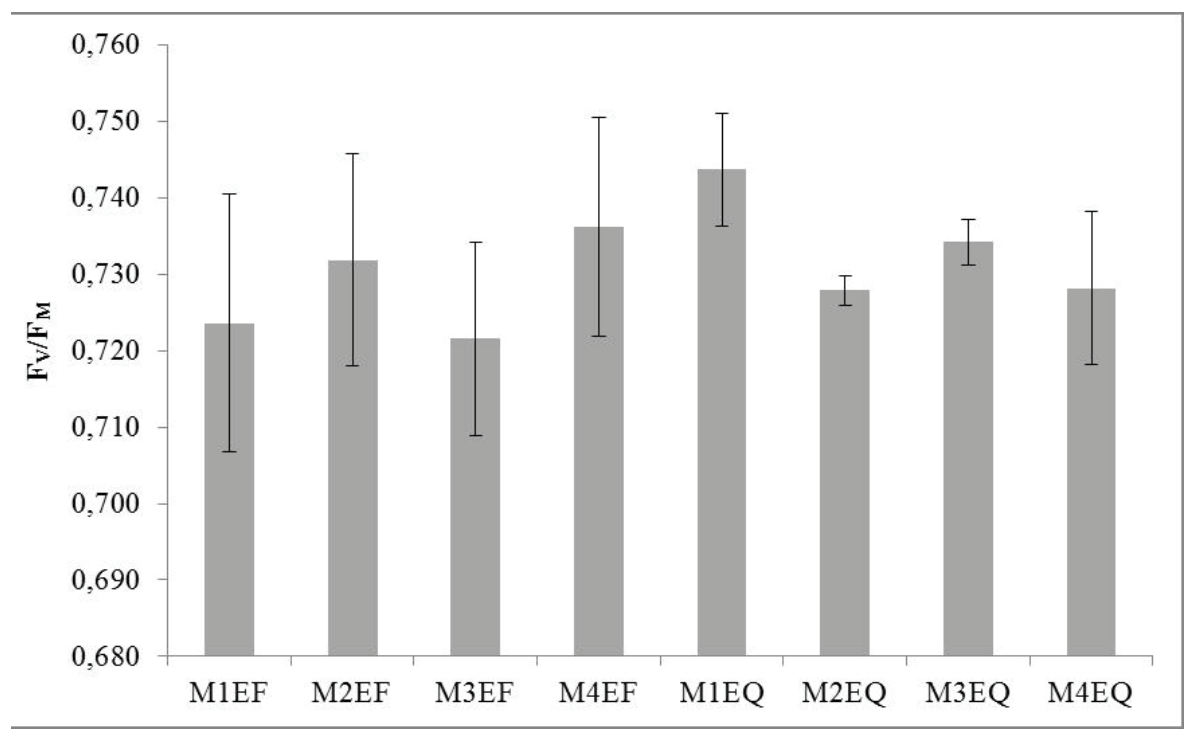

M1: ágar; M2: amido de milho; M3: ágar + amido de milho; M4: ágar + amido de mandioca; EF: esterilização física; EQ: esterilização química.

FIGURA 1- Valores médios e erro-padrão da Relação $\mathrm{F}_{\mathrm{v}} / \mathrm{F}_{\mathrm{m}}$ em mudas de abacaxizeiro 'Gold' (Ananas comosus var. comosus) oriundas de cultivo in vitro, após 90 dias de aclimatização em casa de vegetação.

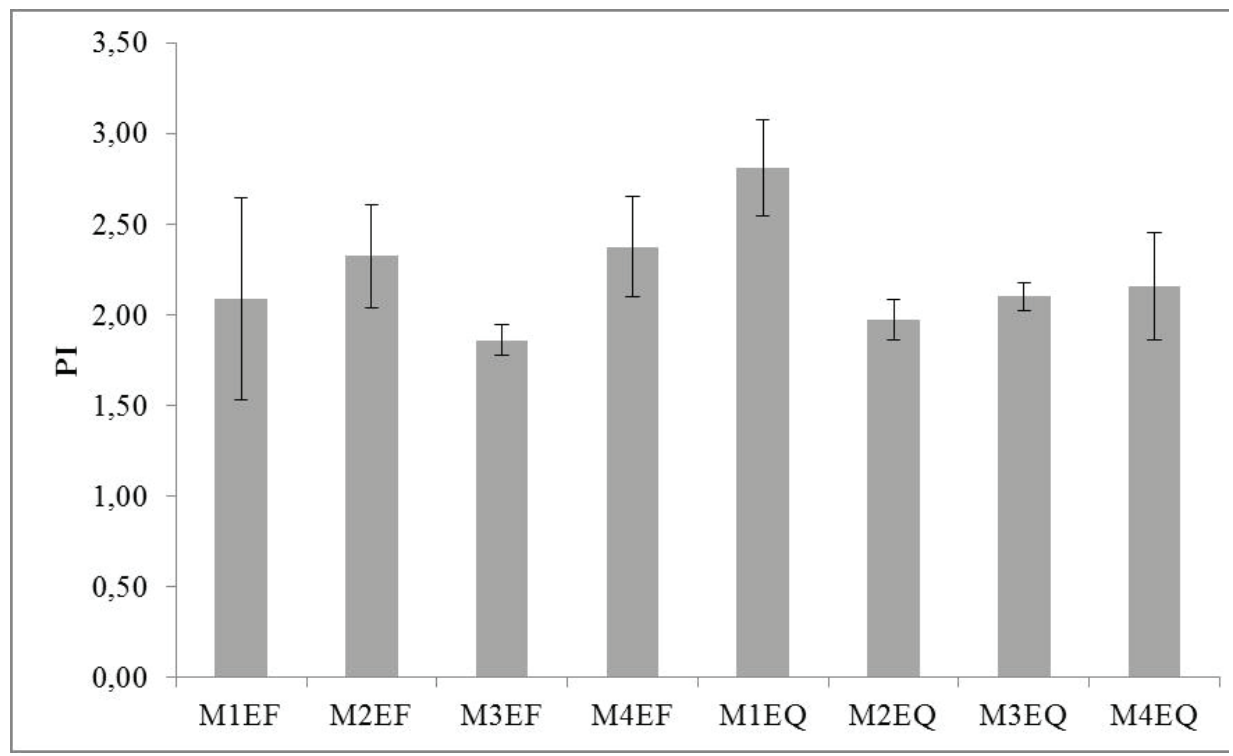

M1: ágar; M2: amido de milho; M3: ágar + amido de milho; M4: ágar + amido de mandioca; EF: esterilização física; EQ: esterilização química.

FIGURA 2- Valores médios e erro-padrão do Índice Fotossintético (PI) em mudas de abacaxizeiro 'Gold' ((Ananas comosus var. comosus)) oriundas de cultivo in vitro, após 90 dias de aclimatização em casa de vegetação. 


\section{CONCLUSÕES}

A partir dos resultados encontrados, é possível concluir que:

- O hipoclorito de sódio foi eficiente na esterilização do meio de cultivo e dos utensílios, sem ocasionar prejuízo ao crescimento e ao desenvolvimento das mudas de abacaxizeiro 'Gold', tanto na fase de enraizamento in vitro quanto na aclimatização.

- O amido de milho puro ou o amido de mandioca, em combinação com o ágar, podem ser usados para geleificar os meios de cultivo na fase de enraizamento in vitro do abacaxizeiro 'Gold'.

- Os meios alternativos propostos não interferiram no desempenho fotossintético das mudas durante a aclimatização.

\section{REFERÊNCIAS}

BARREIRO NETO, M.; LACERDA, J.F.; CARVALHO, R.A.; OLIVEIRA, E.F. Rubi: cultivar de abacaxi resistente à fusariose. Paraíba: Emepa, 2007. $4 p$.

BARTHOLOMEW, D.P. 'MD-2' pineapple transform the world's pineapple fresh fruit export industry. Pineapples News, Honolulu, n. 16, p. 2-5, 2009.

BOLHÀR-NORDENKAMPF, H.R.; LONG, S.P.; BAKER, N.R.; ÖQUIST, G.; SCHREIBERS, U.; LECHNER, E.G. Chlorophyll fluorescence as a probe of the photosynthetic competence of leaves in the field: a review of current instrumentation. Functional Ecology, London, v. 3, p. 497-514, 1989.

COSTA, F.H.S.; PEREIRA, M.A.A.; OLIVEIRA, J.P.; PEREIRA, J.E.S. Efeito de agentes geleificantes alternativos no meio de cultura no cultivo in vitro de abacaxizeiro e bananeira. Ciência Agrotécnica, Lavras, v. 31, n. 1, p. 41-46, 2007.

EMMANUEL, E.; KECK, G.; BLANCHARD, J.; VERMANDE, P.; PERRODIN, Y. Toxicological effects of disinfestation using sodium hypochlorite on aquatic organisms and its contribution to AOX formation in hospital wastewater. Environment International, Oxford, v. 30, p. 891-900, 2004.
ERIG, A.C.; SCHUCH, M.W.; SILVA, L.C. Multiplicação in vitro de macieira (Malus domestica Borkh) cv. Galaxy: meio de cultura e agentes solidificantes alternativos. Revista Brasileira de Agrociência, Pelotas, v. 10, n. 3, p. 297-302, 2004.

FAO. FAOSTAT. Agricultural statistics database: world agricultural information center: 2013. Disponível em: $<$ http://faostat3.fao.org/home/index. html\#HOME>. Acesso em: 25 jun. 2013.

FERRI, V.C.; CENTELLAS, A.Q.; HELBIG, V.E.; FORTES, G.R.L. Uso do ágar, amido e ácido indolbutírico no enraizamento in vitro do portaenxerto de macieira MM111. Revista Ciência Rural, Santa Maria, v. 28, n. 4, p. 561-565, 1998.

IBGE; SIDRA. Quadro comparativo de produção de abacaxi: 2013. Disponível em: http://www.sidra. ibge.gov.br. Acesso em: 25 jun. 2013.

KAO, W.Y.; FORSETH, I.N. Diurnal leaf movement, chlorophyll fluorescence and carbon assimilation in soybean grown under different nitrogen and water availabilities. Plant Cell and Environment, Oxford, v. 15, p. 703-710, 1992.

MURASHIGE, T.; SKOOG, F. A revised medium for rapid growth and bioassays with tobacco tissue cultures. Physiologia Plantarum, Wisconsin, v. 15, p. 473-497, 1962.

PEREIRA, M.R. Simplificação de meios de cultivo para propagação vegetativa in vitro do abacaxizeiro 'Vitória'. Campos dos Goytacazes: UENF, 2011. 41 f. Monografia (Graduação em Agronomia) - Universidade Estadual do Norte Fluminense Darcy Ribeiro, Campos dos Goytacazes, 2011.

REINHARDT, D.H.R.; CUNHA, G.A.P. A propagação do abacaxizeiro. 2. ed. Brasília: Embrapa Informação Tecnológica, 2006. 59p.

RESH, H. Hydroponic food productions. $5^{\text {th }}$ ed. California: Woodbridge Press Publishing Company, 1997. 527p.

RIBEIRO, J. M.; TEIXEIRA, S.L. Multiplicação de Sequoia sempervirens em meio de cultura esterilizado com hipoclorito de sódio. Revista Brasileira de Horticultura Ornamental, Brasília, v. 13, p. 356, 2007. 
SAEG. Sistema para análises estatísticas, versão 9.1: 2007. Viçosa: Fundação Arthur Bernardes, Universidade Federal de Viçosa, 2007.

SAWANT, R.A.; TAWAR, P.N. Use of sodium hypochlorite as media sterilant in sugarcane micropropagation at commercial scale. Sugar Technology, Amsterdam, v. 13, n. 1, p. 27-35, 2011.

SOUZA, A.S.; JUNGHANS, T.G. Introdução à micropropagação de plantas. Cruz das Almas: Embrapa Mandioca e Fruticultura Tropical, 2006. $152 p$.

STRASSER, R.J.; SRIVASTAVA, A.; TSIMILLIMICHAEL, M. Analysis of the chlorophyll a fluorescence transient. In: PAPAGEORGIOU, G.; GOVINDJEE (Ed.). Advances in photosynthesis and respiration chlorophyll fluorescence a signature of photosynthesis. Netherlands: Kluwer Academic Publishers, 2004. v. 19, p 321-362.

STRASSER, R.J.; TSIMILLI-MICHAEL, M.; SRIVASTAVA, A. The fluorescence transient as a tool to characterize and screen photosynthetic samples. In: YUNUS, M.; PATHER, U.; MOHANLY, P. (Ed.). Probing photosynthesis: mechanisms, regulation and adaptation. Basingstoke: Taylor and Francis, 2000. p. 445-483.
TEIXEIRA, S.L.; RIBEIRO, J.M.; TEIXEIRA, M.T. Influence of $\mathrm{NaClO}$ on nutrient medium sterilization and on pineapple (Ananas comosus cv. Smooth Cayenne) behavior. Plant Cell Tissue Organ Culture, Boston, v. 86, p. 375-378, 2006.

TEIXEIRA, S.L.; RIBEIRO, J.M.; TEIXEIRA, M.T. Utilização de hipoclorito de sódio na esterilização de meio de cultivo para multiplicação in vitro de Eucalyptus pellita L. Ciência Florestal, Santa Maria, v. 8, n. 2, p.185-191, 2008.

TIWARI, A.K.; TRIPATHI, S.; LAL, M.; MISHRA, S. Screening of some chemical disinfectants for media sterilization during in vitro micropropagation of sugarcane. Sugar Technology, Amsterdam, v. 14, n. 4, p.364-369, 2012.

VAN HUYLENBROECK, J.M.; PIQUERAS, A.; DEBERGH, P.C. The evolution of photosynthetic capacity and the antioxidant enzymatic system during acclimatization of micropropagated Calathea plants. Plant Science, New York, v. 155, p. 59-66, 2000. 